\title{
Papers
}

\section{Randomised trial of endoscopy with testing for Helicobacter pylori compared with non-invasive $H$ pylori testing alone in the management of dyspepsia}

K E L McColl, L S Murray, D Gillen, A Walker, A Wirz, J Fletcher, C Mowat, E Henry, A Kelman, A Dickson

\begin{abstract}
Objective To compare the efficacy of non-invasive testing for Helicobacter pylori with that of endoscopy (plus H pylori testing) in the management of patients referred for endoscopic investigation of upper gastrointestinal symptoms.

Design Randomised controlled trial with follow up at 12 months.

Setting Hospital gastroenterology unit.

Participants 708 patients aged under 55 referred for endoscopic investigation of dyspepsia, randomised to non-invasive breath test for $H$ pylori or endoscopy plus $H$ pylori testing.

Main outcome measure Glasgow dyspepsia severity score at one year. Use of medical resources, patient oriented outcomes, and safety were also assessed. Results In 586 patients followed up at 12 months the mean change in dyspepsia score was 4.8 in the non-invasive $H$ pylori test group and 4.6 in the endoscopy group (95\% confidence interval for difference -0.7 to $0.5, \mathrm{P}=0.69$ ). Only $8.2 \%$ of patients followed up who were randomised to breath test alone were referred for subsequent endoscopy. The use of non-endoscopic resources was similar in the two groups. Reassurance value, concern about missed pathology, overall patient satisfaction, and quality of life were similar in the two groups. The patients found the non-invasive breath test procedure less uncomfortable and distressing than endoscopy with or without sedation. No potentially serious pathology requiring treatment other than eradication of $H$ pylori was missed.

Conclusion In this patient group, non-invasive testing for $H$ pylori is as effective and safe as endoscopy and less uncomfortable and distressing for the patient. Non-invasive $H$ pylori testing should be the preferred mode of investigation.
\end{abstract}

\section{Introduction}

Over the past 40 years, endoscopy has been used with increasing frequency in the investigation of upper gastrointestinal symptoms. More than 1\% of the population of the United Kingdom undergo gastroscopy each year. ${ }^{1}$ Despite this widespread use of the procedure, a recent qualitative systematic review concluded that "the preponderance of available data does not support the effectiveness of endoscopy in the management of dyspepsia."'

One of the main reasons for performing endoscopy in patients with dyspepsia is to detect underlying ulcer disease. However, non-invasive testing for Helicobacter pylori has been shown to be a useful predictor of endoscopic diagnosis in patients with dyspepsia. In patients without $H$ pylori infection, ulcer disease is extremely rare and endoscopic examination is usually normal or shows evidence of oesophagitis. ${ }^{3-5}$ In dyspeptic patients with $H$ pylori infection, endoscopy shows underlying ulcer disease in 10-50\%. ${ }^{356}$

Considerable interest exists in using non-invasive $H$ pylori testing in place of endoscopy to determine the management of patients presenting with upper gastrointestinal symptoms. Patients with a negative $H$ pylori test could be reassured that they do not have underlying ulcer disease and could be treated symptomatically, as would occur after an endoscopic examination showing no abnormality or evidence of oesophagitis. Patients with a positive $H$ pylori test could all be given treatment to eradicate $H$ pylori, which would cure the subgroup with underlying ulcer disease. Such a strategy involves treating dyspeptic patients positive for $H$ pylori without actual ulcer disease. However, recent meta-analyses indicate that such treatment is superior to placebo in resolving symptoms in $H$ pylori positive non-ulcer dyspepsia and is as effective as any other available treatment for the condition. ${ }^{7-9}$ In addition, other indications support eradication of the infection in non-ulcer dyspepsia-for example, removal of the increased risk of developing actual ulcer disease, ${ }^{10-12}$ removal of an important risk factor for gastric cancer and lymphoma, ${ }^{13}{ }^{14}$ and removal of concern about a potential adverse interaction between the infection and subsequent long term use of proton pump inhibitor treatment. $^{15}$

Non-endoscopic management would be inappropriate for certain groups of patients, including those with symptoms suggestive of underlying malignancy and those taking non-steroidal anti-inflammatory drugs, who may develop ulcer disease in the absence of $H$ pylor $i$ infection. Non-endoscopic management might

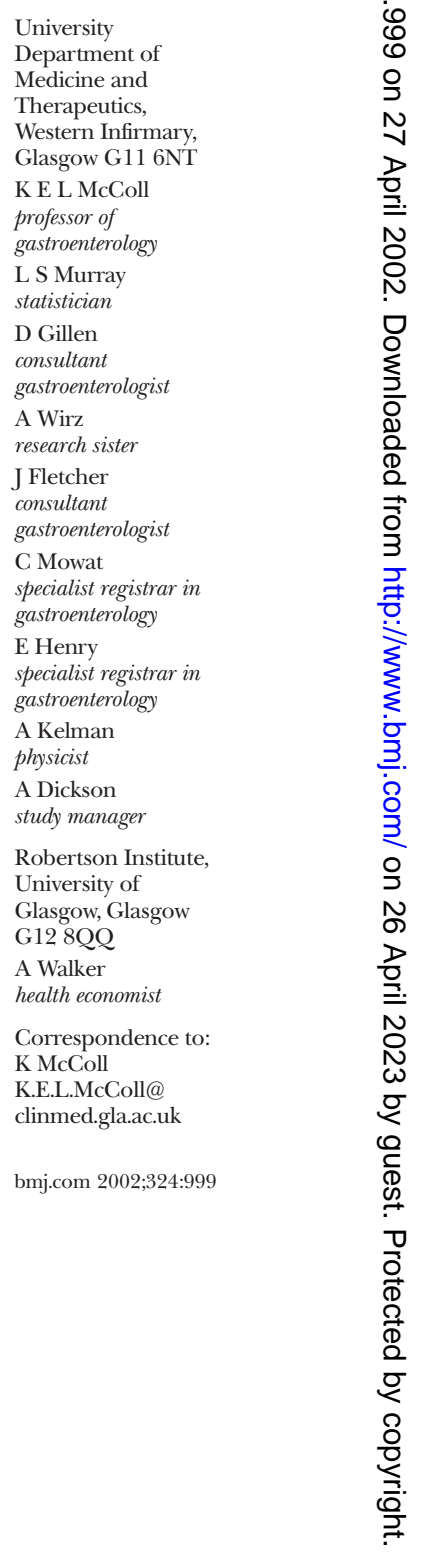


also be inappropriate in older patients because of the higher incidence of malignancy in this age group.

We present the results of a randomised trial comparing non-invasive testing for $H$ pylori with endoscopy in the management of patients referred for endoscopic investigation of upper gastrointestinal symptoms.

\section{Methods}

The ethics committees of the West Glasgow University NHS Trust and the local primary care trust approved the study. We recruited participants from patients referred by their general practitioners to the hospital for endoscopic investigation of upper gastrointestinal symptoms. Exclusion criteria were age over 55, the use of non-steroidal anti-inflammatory drugs (excluding low dose aspirin), and the presence of sinister symptoms. We selected patients by examining all referral letters to the hospital's gastroenterology outpatient clinics and open access endoscopy service. All patients whose referral letter indicated upper gastrointestinal symptoms and age under 55 years and made no comment about the presence of sinister symptoms or use of non-steroidal anti-inflammatory drugs were sent an appointment for our one stop clinic established specifically for the study. The appointment letter for the clinic informed patients that they might be invited to participate in a study comparing endoscopy with a non-invasive breath test. They were also told to stop any antisecretory drugs two weeks before the clinic appointment.

\section{Baseline assessment}

At their single visit to the clinic, the patients had a structured interview by either a consultant gastroenterologist or a specialist registrar in gastroenterology. Details recorded included the character of the patient's predominant symptom and any history of use of nonsteroidal anti-inflammatory drugs or other drugs. Patients were specifically asked about the presence of any of the following sinister symptoms: dysphagia, recent weight loss of more than $3 \mathrm{~kg}$, persistent vomiting, first degree relative with upper gastrointestinal malignancy, recent evidence of upper gastrointestinal bleeding, or history of gastric surgery. We assessed the severity of symptoms over the six months preceding the visit with a previously validated instrument, the Glasgow dyspepsia severity score. ${ }^{16}$ This score measures the frequency of upper gastrointestinal symptoms $(0-5)$, their effect on normal activities (0-2), number of days of work missed because of symptoms (0-2), frequency of medical consultations (0-2), frequency of home visits (0-2), tests for dyspepsia (0-2), and use of over the counter (0-2) and prescribed (0-3) drugs. The total score ranges from 0 to 20 , with higher scores indicating more severe dyspepsia.

We assessed quality of life with a 36 item medical outcomes study short form health survey (SF-36), which examines eight aspects of quality of life: general and mental health, physical function, social function, physical and emotional health, pain, and vitality. ${ }^{17}$ The scores for each of the eight aspects can range from 0 (worst) to 100 (best). We asked patients about their degree of worry about their condition and about their degree of concern that they might have a sinister underlying disease. These were recorded on a 0-10 Likert-type scale. We also performed abdominal examination and recorded evidence of tenderness, organomegaly, or abdominal mass. The information obtained from the structured questions and examination was entered directly into a personal computer.

\section{Intervention}

We then invited all eligible patients to participate in the study by being randomised to endoscopy plus breath test for $H$ pylori or breath test alone. We informed patients that recent studies indicated that the breath test may be as useful as endoscopy in determining appropriate management. We also informed them that they, or their general practitioner, would be free to request an early endoscopy if either felt that it was indicated.

After participants had given written, informed consent, we opened a sealed envelope that randomly allocated each patient to one or the other investigation strategy. The pharmacy department carried out the randomisation independently by using tables of random numbers to assign half the patients to each investigation strategy. Immediately after this, patients underwent either endoscopy plus the breath test or the breath test alone. Patients had their throat sprayed with lignocaine before endoscopy and were also offered intravenous sedation with midazolam. During the endoscopy, we took biopsies from both the antrum and body region for histology and urease slide test (CLO test; Delta West, Beatley, Australia). We performed the ${ }^{14} \mathrm{C}$-urea breath test as previously described, ${ }^{18}$ except that we used a citric acid drink in place of a fatty drink in order not to obscure the endoscopic view. The patients randomised to endoscopy also underwent the breath test, as this provided a quicker determination of their $H$ pylori status than awaiting the result of the histology or urease test on their gastric biopsies. The breath test was analysed on site, and the result was available within 30 minutes.

The medical gastroenterologist saw patients again immediately after their tests and informed them of the findings. Patients who had received sedation for the endoscopy were seen one to two hours later. Patients who had undergone endoscopy were informed of the findings and of their H pylori status. If they were H pylori positive, we advised them to take eradication treatment irrespective of the presence or absence of ulcer disease. Patients who had only the breath test were informed of the result. If it was positive, we told them that they might have an underlying ulcer that would benefit from treatment of the infection and that studies in our population also indicated symptomatic benefit from treating the infection even in the absence of an ulcer. ${ }^{10}$ We reassured patients with a negative breath test result that they were very unlikely to have an ulcer and that their symptoms were likely to be due to gastrooesophageal reflux disease or non-ulcer dyspepsia. All patients testing positive for $H$ pylori were given a seven day course of $H$ pylori eradication treatment consisting of omeprazole $20 \mathrm{mg}$ twice daily, clarithromycin 250 $\mathrm{mg}$ three times daily, and amoxycillin $500 \mathrm{mg}$ three times daily. Patients who were allergic to amoxycillin were given metronidazole $400 \mathrm{mg}$ three times daily in its place. The clinic did not provide or recommend directly any other treatment. All patients were told to 
see their general practitioner for further treatment if their symptoms persisted.

Before they left the clinic, we asked patients to score the degree of discomfort or distress caused by their diagnostic test on an 0-6 integer scale. In addition, we asked them if they would have the same test again happily, reluctantly, or never. We asked patients who had had an endoscopy whether they would have it again with or without sedation.

We then discharged the patients back to the care of their general practitioner. We sent a standardised letter to the general practitioner stating the results of the tests and whether or not $H$ pylori eradication treatment had been prescribed. The letter also informed the general practitioner that open access breath testing was available to check whether the infection had been eradicated. We told the general practitioners that a negative breath test indicated that the symptoms were likely to be due to non-ulcer dyspepsia or gastrooesophageal reflux disease.

\section{Follow up}

One year after randomisation, we asked the patients to attend an interview by non-medical, non-nursing staff for documentation of outcome. At that time, the Glasgow dyspepsia severity score and the SF-36 quality of life assessment were repeated. Details were also obtained from the patient about visits to the general practitioner or hospital for dyspepsia or other conditions, further investigations, and use of prescribed and over the counter drugs for dyspepsia or other conditions since randomisation. We used a computer based questionnaire to obtain this information. Most patients were able to interact directly with the computer, and assistance was provided as required. In addition, patients were asked about their concern regarding their condition, their concern about possible missed underlying disease, and their overall satisfaction with their initial investigation and management. These factors were assessed by asking the patient to place a mark on a Likert-type scale. The patients also had a ${ }^{14} \mathrm{C}$-urea breath test to re-check their H pylori status.

\section{Power calculation}

The planned study of 672 patients (436 positive for $H$ pylori, 236 negative for $H$ pylori) followed up at one year had $90 \%$ power to detect a difference in mean change in the Glasgow dyspepsia severity score of 1.03 in the $H$ pylori positive subgroup and 1.41 in the $H$ pylori negative subgroup at the $5 \%$ significance level overall (2.5\% per subgroup). The expected proportion of $65 \%$ pylori positive cases was based on an earlier study in our population with dyspepsia. The standard deviation of the change in dyspepsia score was assumed to be 3.5 .

\section{Statistical analysis}

We compared the two treatment groups by using the two sample $t$ test or the Mann-Whitney $\mathrm{U}$ test, as appropriate. We compared categorical data by using the $\chi^{2}$ test, and we used analysis of variance to compare subgroups. We determined 95\% confidence intervals where appropriate. We used the statistical package Minitab version 13 to make calculations, and made no correction in the subgroup analysis for multiple testing.

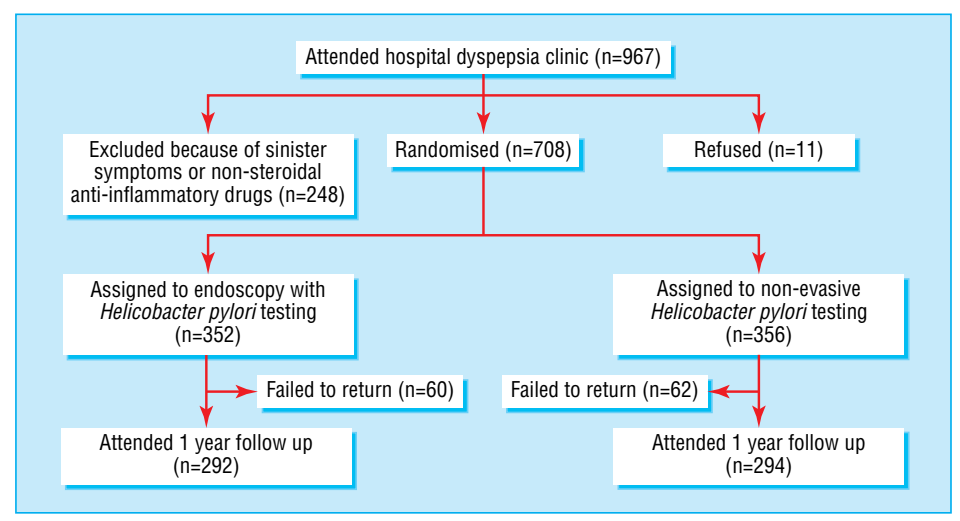

Fig 1 Flow chart of recruitment

\section{Results}

Over the two year recruitment period from October 1997 to October 1999, we saw 967 patients aged under 55 at the one stop dyspepsia clinic, which represented $81 \%$ of those who had been sent appointments. Of these 967 patients, 248 were not eligible for randomisation because of sinister symptoms or use of non-steroidal anti-inflammatory drugs and 11 refused randomisation (fig 1).

The predominant symptom was recorded in 705 of the 708 patients randomised and was epigastric pain or discomfort in $380(54 \%)$, heartburn or acid reflux in $207(29 \%)$, and a variety of other upper gastrointestinal symptoms in the remainder. The mean age of patients randomised was 36 (range 17-57) years, and 377 (53\%) were men. The prevalence of $H$ pylori infection was $50 \%(352 / 708)$.

In total, 352 patients were randomised to endoscopy with $H$ pylori testing and 356 patients to non-invasive $H$ pylori testing alone. The prevalence of H pylori infection was $51 \%(181 / 352)$ in the endoscopy plus breath test group and $48 \%(171 / 356)$ in the breath test alone group; the two groups were also similar in other respects (tables 1 and 2). Table 3 shows the endoscopic findings in the patients randomised to that investigation, subclassified according to predominant symptom and $H$ pylori status.

One year after randomisation $292(83 \%)$ of the 352 patients randomised to endoscopy and 294 (83\%) of the 356 patients randomised to non-invasive $H$ pylori

Table 1 Characteristics of the two groups at randomisation. Values are numbers (percentages) unless stated otherwise

\begin{tabular}{|c|c|c|}
\hline & $\begin{array}{l}\text { Endoscopy plus } \\
\text { breath test } \\
(\mathrm{n}=352)\end{array}$ & $\begin{array}{l}\text { Breath test alone } \\
\qquad(\mathrm{n}=356)\end{array}$ \\
\hline Mean (SD; range) age in years & $35.5(9.4 ; 17-54)$ & $36.6(8.9 ; 18-57)$ \\
\hline Male & 190/352 (54) & $187 / 356(53)$ \\
\hline Smokers & 133/349 (38) & 161/353 (46) \\
\hline Helicobacter pylori positive & $181 / 352(51)$ & $171 / 356(48)$ \\
\hline Mean (SD; range) Glasgow dyspepsia severity score & $10.2(2.1 ; 4-16)$ & $10.3(2.3 ; 4-16)$ \\
\hline $\begin{array}{l}\text { Median duration of dyspepsia (scored }<0.5,0.5-2,2-5,5-10 \text {, } \\
>10 \text { years) }\end{array}$ & $2-5$ years & $2-5$ years \\
\hline $\begin{array}{l}\text { Proportion taking prescribed antisecretory drugs most days in } \\
\text { previous six months }\end{array}$ & $116 / 352(33)$ & 132/355 (37) \\
\hline Heartburn or acid reflux as predominant symptom & $87 / 352(25)$ & $120 / 353(34)$ \\
\hline Epigastric pain or discomfort as predominant symptom & 199/352 (57) & $181 / 353(51)$ \\
\hline Mean (SD; range) concern about condition (0-10 scale) & $5.0(2.2 ; 0-10)$ & $5.2(2.4 ; 0-10)$ \\
\hline $\begin{array}{l}\text { Mean (SD; range) concern about underlying serious disease } \\
\text { (0-10 scale) }\end{array}$ & $4.1(2.4 ; 0-10)$ & $4.4(2.4 ; 0-10)$ \\
\hline
\end{tabular}


Table 2 Median (interquartile range) SF-36 quality of life scores

\begin{tabular}{|c|c|c|c|c|c|c|}
\hline & At pres & ntation & At or & year & Impro & ment \\
\hline & $\begin{array}{c}\text { Endoscopy plus } \\
\text { breath test } \\
(\mathrm{n}=349)\end{array}$ & $\begin{array}{c}\text { Breath test } \\
\text { alone }(n=352)\end{array}$ & $\begin{array}{c}\text { Endoscopy plus } \\
\text { breath test } \\
(\mathrm{n}=283)\end{array}$ & $\begin{array}{c}\text { Breath test } \\
\text { alone ( } \mathrm{n}=289)\end{array}$ & $\begin{array}{c}\text { Endoscopy plus } \\
\text { breath test } \\
(\mathrm{n}=283)\end{array}$ & $\begin{array}{c}\text { Breath test } \\
\text { alone }(\mathrm{n}=289)\end{array}$ \\
\hline Physical functioning & 95 (80 to 100$)$ & 90 (80 to 100$)$ & 95 (85 to 100$)$ & 95 (85 to 100$)$ & 0 (0 to 5$)$ & 0 (0 to 10$)$ \\
\hline Role functioning - physical & 100 (50 to 100 ) & 100 (50 to 100$)$ & 100 (75 to 100$)$ & 100 (75 to 100$)$ & 0 (0 to 25) & 0 (0 to 25$)$ \\
\hline Bodily pain & 61 (42 to 74 ) & 56 (41 to 74 ) & 72 (52 to 84 ) & 72 (51 to 100$)$ & $9(-10$ to 26$)$ & 10 (0 to 28$)$ \\
\hline General health & 65 (47 to 77 ) & 62 (57 to 77 ) & 72 (52 to 82 ) & 72 (52 to 82 ) & $2(-5$ to 12$)$ & 5 (-5 to 15$)$ \\
\hline Vitality & 50 (40 to 70 ) & 50 (35 to 65$)$ & 55 (40 to 70$)$ & 60 (40 to 75 ) & $5(-10$ to 15$)$ & 5 (-5 to 20$)$ \\
\hline Social functioning & 75 (62 to 100$)$ & 75 (50 to 100$)$ & 87 (62 to 100$)$ & 87 (62 to 100 ) & 0 (0 to 25$)$ & 0 (0 to 25$)$ \\
\hline Role functioning-emotions & 100 (33 to 100$)$ & 100 (33 to 100$)$ & 100 (33 to 100$)$ & 100 (33 to 100$)$ & $0(0$ to 33$)$ & 0 (0 to 33 ) \\
\hline Mental health & 68 (54 to 84 ) & 68 (52 to 80 ) & 72 (60 to 84) & 76 (58 to 88 ) & 0 (-8 to 16$)$ & $4(-4$ to 12$)$ \\
\hline
\end{tabular}

testing could be reassessed (fig 1 ). The $H$ pylori eradication rates at one year in the two groups were $79 \%$ $(119 / 150)$ and $84 \%(118 / 141)$.

\section{Primary outcome}

The primary outcome measured was the Glasgow dyspepsia severity score. One year after randomisation, the mean change in score was similar in the endoscopy and non-invasive $H$ pylori testing groups at 4.8 and 4.6 (95\% confidence interval for difference -0.7 to 0.5 , $\mathrm{P}=0.69$ ). This represented a mean reduction in dyspepsia score since initial assessment of $46 \%$ in patients randomised to endoscopy and $45 \%$ in those randomised to the breath test. The mean scores at one year were similar at 5.4 and 5.6 in the two groups. The proportion of patients with complete resolution of dyspepsia (score $<2$ ) was similar in the two groups at $42 / 291(14 \%)$ and $33 / 293(11 \%)(-2 \%$ to $9 \%$ for difference, $\mathrm{P}=0.25$ ).

The mean change in score in the $H$ pylori positive patients was 5.4 in the endoscopy group and 5.0 in the breath test group ( -1.2 to 0.5 for difference, $\mathrm{P}=0.38$ ). In the $H$ pylori negative patients the corresponding figures were 4.0 and 4.3 ( -0.5 to $1.0, \mathrm{P}=0.48$ ).

\section{Subsequent use of medical resources}

The two groups were similar at one year with respect to proportions attending their general practitioner and hospital and use of prescribed and over the counter drugs over the 12 month period since randomisation (table 4). They were also similar with respect to repeat referral for further non-endoscopic investigations (table 4).

The subsequent use of endoscopy differed only slightly between the randomised groups. Of the 292 patients randomised to initial endoscopy and followed up, five $(1.7 \%)$ were referred for a further endoscopy, compared with $24(8.2 \%)$ of the 294 patients

Table 3 Endoscopic diagnosis and relation to Helicobacter pylori status and predominant symptom in patients randomised to endoscopy plus $H$ pylori testing. Values are numbers of patients

\begin{tabular}{|c|c|c|c|c|}
\hline \multirow[b]{2}{*}{ Diagnosis } & \multicolumn{2}{|c|}{ H pylori positive $(\mathrm{n}=172)$} & \multicolumn{2}{|c|}{ H pylori negative ( $\mathrm{n}=165)$} \\
\hline & $\begin{array}{l}\text { Heartburn or } \\
\text { acid reflux } \\
(\mathrm{n}=37)\end{array}$ & $\begin{array}{c}\text { Other } \\
\text { symptom } \\
(\mathrm{n}=135)\end{array}$ & $\begin{array}{l}\text { Heartburn or } \\
\text { acid reflux } \\
(\mathrm{n}=49)\end{array}$ & $\begin{array}{c}\text { Other } \\
\text { symptom } \\
\text { (n=116) }\end{array}$ \\
\hline Normal & 24 & 94 & 38 & 95 \\
\hline Oesophagitis grade I & 9 & 9 & 8 & 15 \\
\hline Oesophagitis grade II & 1 & 2 & 2 & 1 \\
\hline Gastric ulcer (including prepyloric ulcer) & - & 9 & - & 2 \\
\hline Duodenal ulcer & 3 & 19 & 1 & 3 \\
\hline Gastric ulcer plus duodenal ulcer & - & 1 & - & - \\
\hline Low grade MALToma & - & 1 & - & - \\
\hline
\end{tabular}

randomised to initial non-invasive $H$ pylori testing (95\% confidence interval for difference $3 \%$ to $10 \%$, $\mathrm{P}<0.001)$.

\section{Patient oriented outcome}

One year after randomisation, mean overall concern of patients about their disease and concern about missed pathology were similar in the two groups (table 4). The relative reassurance after non-invasive $H$ pylori testing compared with endoscopy was unaffected by the magnitude of concern about serious disease at the time of randomisation (fig 2). Overall satisfaction with initial investigation and management (table 4) and SF-36 quality of life scores at one year after randomisation were similar in the two groups (table 2).

We also assessed the patients' experience of the two investigational procedures on an integer scale of 0 to 6 , with 0 indicating no recollection, 1 no discomfort, and 6 severe distress. After the breath test, $96 \%$ of patients gave the test a score of 1 , whereas only $13 \%$ of patients randomised to endoscopy had a score of 0 or $1(95 \%$ confidence interval for difference $78 \%$ to $87 \%$, $\mathrm{P}=0.000$ ) (table 5). Of the patients randomised to endoscopy, 20\% elected to have intravenous sedation with midazolam. Of those sedated, $32 \%$ could not remember the procedure, and the median score in the remainder was 2 . The median score after the endoscopy without sedation was 4 . After non-invasive H pylori testing, 341/342 (99.7\%) said they would happily have it again compared with 38/66 (58\%) after endoscopy with sedation and 79/256 (31\%) after endoscopy without sedation. After endoscopy without

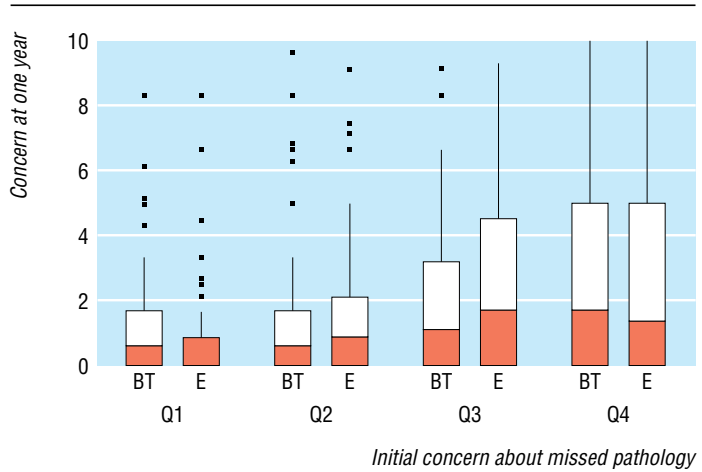

Fig 2 Box and whisker plots showing range, quarters, and median scores for concern about missed pathology at one year in the two groups, subdivided according to quarter (Q1-Q4) of concern at initial assessment. Points denote outliers. In some cases, minimum, Q1, and median are all 0. BT=non-invasive breath test for Helicobacter pylori; $\mathrm{E}=$ =ndoscopy plus $\mathrm{H}$ pylori testing 
sedation, 66/253 (26\%) said they would take sedation if they had to have the procedure again.

\section{Safety}

Table 3 shows the endoscopic diagnoses in the patients randomised to initial endoscopy. The only potentially serious abnormality detected was a low grade gastric MALToma (mucosal associated lymphoid tumour) identified in a routine biopsy from one of the $H$ pylori positive patients. Further investigation indicated that this was confined to the gastric mucosa and needed no treatment other than the H pylori eradication treatment that had been given under the routine study protocol. The endoscopic diagnosis in the 24 patients randomised to non-invasive $H$ pylori testing and then referred later for endoscopy showed no abnormality in 17 patients, oesophagitis grade I in three, oesophagitis grade II in two, and duodenal ulcer in one; the remaining patient could not tolerate the examination. There was no evidence of $H$ pylori in the patient with the duodenal ulcer. Repeat endoscopic examination was normal in the five patients randomised initially to endoscopy and referred for further endoscopy.

\section{Subgroup analysis}

We analysed the results to see if the outcome of the two investigation strategies was affected by $H$ pylori status and character of symptoms at presentation (table 6). The outcomes were similar in the two treatment strategies in patients who were $H$ pylori negative compared with those who were positive and in patients with predominant heartburn or reflux symptoms compared with those with other predominant symptoms. Analysis of variance fitting treatment, $H$ pylori status, and symptom at presentation as main effects showed no evidence of a significant treatment effect on Glasgow dyspepsia severity score $(\mathrm{P}=0.95)$, worry about condition $(\mathrm{P}=0.55)$, concern about missed pathology $(\mathrm{P}=0.48)$, or satisfaction $(\mathrm{P}=0.89)$.

\section{Discussion}

The use of simple non-invasive testing for $H$ pylori in place of endoscopy in determining the management of
Table 4 Comparison of the two randomised groups over subsequent year. Values are numbers (percentages) unless stated otherwise

\begin{tabular}{|c|c|c|}
\hline & $\begin{array}{l}\text { Endoscopy plus breath } \\
\text { test }(\mathrm{n}=292)\end{array}$ & $\begin{array}{l}\text { Breath test alone } \\
\quad(n=294)\end{array}$ \\
\hline Mean (SD; range) Glasgow dyspepsia severity score & $5.4(3.4 ; 0-15)$ & $5.6(3.4 ; 0-15)$ \\
\hline \multicolumn{3}{|l|}{ Frequency of: } \\
\hline Visit to general practitioner for dyspepsia & 98/292 (34) & 108/293 (37) \\
\hline $\begin{array}{l}\text { Attendance at hospital outpatient clinic for } \\
\text { dyspepsia }\end{array}$ & $19 / 292(7)$ & $18 / 293(6)$ \\
\hline Endoscopy & $4 / 292(1)$ & $24 / 294(8)$ \\
\hline $\begin{array}{l}\text { Repeat breath test (in patients testing positive } \\
\text { on entry) }\end{array}$ & $27 / 292(9)(26 / 156(17))$ & 19/294 (6) (18/142 (13)) \\
\hline Barium meal & $5 / 292(2)$ & $1 / 294(0.3)$ \\
\hline Ultrasonography & $3 / 292(1)$ & $10 / 294(3)$ \\
\hline Other gastrointestinal investigations & $11 / 292(4)$ & $7 / 294(2)$ \\
\hline \multicolumn{3}{|l|}{ Drug usage (\% treated) (median length of treatment): } \\
\hline Proton pump inhibitor & 69/291 (24) (24 weeks) & 77/292 (26) (20 weeks) \\
\hline $\mathrm{H}_{2}$ receptor antagonist & 56/291 (19) (10 weeks) & 68/293 (23) (20 weeks) \\
\hline Antacids & 82/291 (28) (18 weeks) & 90/293 (31) (10 weeks) \\
\hline Alginates & 73/290 (25) (12 weeks) & 82/291 (28) (6 weeks) \\
\hline \multicolumn{3}{|c|}{ Patient oriented outcomes (0-10: $0=$ no concern, $10=$ extreme concern) } \\
\hline Mean (SD; range) overall concern about symptoms & $2.4(2.6,0-10)$ & $2.4(2.4 ; 0-10)$ \\
\hline Mean (SD; range) concern about missed disease & $1.7(2.3 ; 0-10)$ & $1.9(2.5 ; 0-10)$ \\
\hline $\begin{array}{l}\text { Mean (SD; range) overall satisfaction with } \\
\text { management }\end{array}$ & $8.9(1.6 ; 0.8-10)$ & $8.9(1.7 ; 0-10)$ \\
\hline
\end{tabular}

patients with uncomplicated dyspepsia has been the subject of debate for several years. This large prospective randomised study indicates that non-invasive $H$ pylori testing is as effective and safe as endoscopy and is less uncomfortable and distressing for the patient.

The primary outcome was the Glasgow dyspepsia severity score. This was similar at one year in the two randomised groups, having fallen by $46 \%$ since entry in the endoscopy group and by $45 \%$ in the breath test alone group. A strength of the study was that it also assessed a wide range of other relevant outcomes, including subsequent use of medical resources, patient oriented outcomes, and safety.

\section{Use of endoscopy}

Subsequent use of endoscopy in patients randomised to non-invasive $H$ pylori testing was low at $8.2 \%$ and only slightly higher than the $1.7 \%$ use of repeat endoscopy in patients randomised to initial endoscopy. The

Table 5 Discomfort score recorded after breath test alone, endoscopy with sedation, and endoscopy without sedation. Values are numbers (percentages)

\begin{tabular}{|c|c|c|c|c|c|c|c|c|}
\hline & $\begin{array}{c}\text { Cannot } \\
\text { remember } \\
0\end{array}$ & $\begin{array}{c}\text { No discomfort } \\
1\end{array}$ & 2 & 3 & 4 & 5 & $\begin{array}{c}\text { Severe distress } \\
6\end{array}$ & $\begin{array}{c}\text { Total }(\mathrm{n}=\mathbf{6 6 1}) \\
7\end{array}$ \\
\hline Breath test alone & 0 & $327(95.6)$ & $9(26)$ & $2(0.6)$ & $3(0.9)$ & 0 & $1(0.3)$ & 342 \\
\hline Endoscopy with sedation & $20(31.7)$ & $14(22.2)$ & $12(19.0)$ & $4(6.3)$ & $4(6.3)$ & $6(9.5)$ & $3(4.8)$ & 63 \\
\hline Endoscopy without sedation & 0 & $8(3.1)$ & $50(19.5)$ & $64(25)$ & 39 (15.2) & $70(27.3)$ & $25(9.8)$ & 256 \\
\hline
\end{tabular}

Table 6 Mean outcome scores (SD; range) at one year subdivided by Helicobacter pylori status and predominant symptom at initial presentation

\begin{tabular}{|c|c|c|c|c|c|c|c|c|}
\hline & \multicolumn{4}{|c|}{ Positive for $H$ pylori } & \multicolumn{4}{|c|}{ Negative for $H$ pylori } \\
\hline & \multicolumn{2}{|c|}{ Heartburn or acid reflux } & \multicolumn{2}{|c|}{ Other } & \multicolumn{2}{|c|}{ Heartburn or acid reflux } & \multicolumn{2}{|c|}{ Other } \\
\hline & $\begin{array}{l}\text { Endoscopy plus } \\
\text { breath test } \\
(\mathrm{n}=41)\end{array}$ & $\begin{array}{l}\text { Breath test alone } \\
\quad(n=64)\end{array}$ & $\begin{array}{l}\text { Endoscopy plus } \\
\text { breath test } \\
(\mathrm{n}=95)\end{array}$ & $\begin{array}{l}\text { Breath test alone } \\
\quad(n=87)\end{array}$ & $\begin{array}{l}\text { Endoscopy plus } \\
\text { breath test } \\
(\mathrm{n}=34)\end{array}$ & $\begin{array}{l}\text { Breath test alone } \\
\quad(n=34)\end{array}$ & $\begin{array}{l}\text { Endoscopy plus } \\
\text { breath test } \\
(n=121)\end{array}$ & $\begin{array}{c}\text { Breath test } \\
\text { alone }(n=105)\end{array}$ \\
\hline $\begin{array}{l}\text { Glasgow dyspepsia } \\
\text { severity score }(0-20)\end{array}$ & $6.0(2.8 ; 1-13)$ & $6.4(3.1 ; 1-15)$ & $6.2(3.4 ; 1-15)$ & $5.7(3.1 ; 0-14)$ & $5.4(3.2 ; 1-14)$ & $6.1(3.4 ; 1-14)$ & $4.6(3.6 ; 0-13)$ & $4.8(3.8 ; 1-16)$ \\
\hline $\begin{array}{l}\text { Worry about condition } \\
(0-10)\end{array}$ & $2.2(2.2 ; 0-8)$ & $2.4(2.5 ; 0-9.5)$ & $2.6(2.5 ; 0-10)$ & $2.8(2.5 ; 0-10)$ & $3.3(2.9 ; 0-8.5)$ & $2.7(2.7 ; 0-8)$ & $2.2(2.6 ; 0-10)$ & $1.8(2.2 ; 0-9)$ \\
\hline $\begin{array}{l}\text { Concern about missed } \\
\text { disease }(0-10)\end{array}$ & $1.5(1.9 ; 0-7.2)$ & $1.9(2.4 ; 0-9.3)$ & $1.5(2.1 ; 0-10)$ & $2.1(2.5 ; 0-10)$ & $2.2(2.7 ; 0-8.3)$ & $1.92 .6 ; 0-10)$ & $1.8(0.4 ; 0-9.7)$ & $1.6(2.4 ; 0-10)$ \\
\hline $\begin{array}{l}\text { Overall satisfaction with } \\
\text { management }(0-10)\end{array}$ & $8.9(1.6 ; 5-10)$ & $8.8(1.9 ; 1.7-10)$ & $8.8(1.7 ; 1.7-10)$ & $8.5(1.8 ; 5-10)$ & $9.1(1.1 ; 5-10)$ & $9.3(1.0 ; 5-10)$ & $8.9(1.7 ; 0.8-10.0)$ & $9.4(1.5 ; 0-10)$ \\
\hline
\end{tabular}


use of endoscopy over the 12 month follow up was thus reduced by $94 \%$ in patients randomised to non-invasive $H$ pylori testing. This marked reduction in endoscopy was not accompanied by any subsequent increased use of other medical resources. Non-invasive $H$ pylori testing is substantially cheaper than endoscopy, and its use will therefore reduce the overall cost of medical care.

\section{Reassurance of patients and acceptability of procedure}

Previous studies have shown that endoscopic examination is helpful, even if results are negative, as it reassures patients and reduces their overall concern. ${ }^{19}{ }^{20}$ Our study has shown that non-invasive $H$ pylori testing is equivalent to endoscopy in this respect. It is often assumed that non-endoscopic investigation strategies will be inappropriate for patients who are particularly worried about an underlying serious disease at initial presentation. However, our study indicated that the most worried patients had equivalent reassurance from endoscopy and non-invasive breath test.

Another important consideration in deciding which investigation to use is the acceptability of the procedure itself to the patient. Patients found the breath test less uncomfortable and distressing than endoscopy. Endoscopy is now usually performed without sedation, and most patients found this procedure distressing and expressed unwillingness to undergo the experience again.

\section{Safety}

A concern about widespread implementation of non-invasive $H$ pylori testing in place of endoscopy is that upper gastrointestinal malignancy may be missed in some patients. For that reason, we excluded patients with sinister symptoms and those aged 55 or over. A previous retrospective study in our catchment area ${ }^{21}$ and one from another region in the United Kingdom ${ }^{22}$ indicated that underlying malignancy in such patients presenting for endoscopy was extremely rare and when present was rarely curable. In this study, of the 352 patients who were randomised to initial endoscopy only one had a potentially serious condition. He had a normal endoscopy but was positive for $H$ pylori and was found to have low grade MALToma in one of the gastric biopsies taken as part of the study protocol. This condition fully resolved with the standard $H$ pylori eradication treatment that he had received as part of the study and before the histology became available. Consequently, this patient would not have been adversely affected by being randomised to noninvasive $H$ pylori testing and eradication.

There is particular concern currently about the rising incidence of carcinoma at the gastro-oesophageal junction and of premalignant Barrett's oesophagus. ${ }^{23}$ Our region has the highest reported incidence of this cancer in the world. ${ }^{24}$ Despite this, not a single case of Barrett's oesophagus, severe oesophagitis (> grade II), or gastro-oesophageal junction malignancy occurred in our 352 patients recorded and randomised to endoscopy. Excluding patients with dysphagia and those aged over 55 seems to be an effective means of excluding potentially serious disease of the gastrooesophageal junction.

\section{Effect of predominant symptom}

We included patients with the full spectrum of upper gastrointestinal symptoms, including patients whose symptoms indicated gastro-oesophageal reflux disease. Subanalysis of our results indicated that the two investigation strategies were equivalent in the patients with heartburn or reflux as well as in patients with more ulcer-like symptoms (table 6). The endoscopy, therefore, added no discernible value to the breath test in the management of either group of patients.

The prevalence of ulcers in the patients positive for $H$ pylori with predominant heartburn or reflux symptoms was only $8 \%$, which was significantly less than the $21 \%$ found in the $H$ pylori positive patients with other upper gastrointestinal symptoms and little higher than the $4 \%$ seen in $H$ pylori negative patients (table 3). The value of the test and eradicate $H$ pylori strategy in the patients with heartburn or reflux was therefore relatively small, at least with respect to cure of underlying ulcers. It has recently been proposed that this strategy should be limited to patients with more ulcer-like symptoms, as this reduces the number of patients receiving $H$ pylori treatment for each ulcer cured.$^{25}$ However, there are arguments both in favour of and against treating $H$ pylori in patients with gastrooesophageal reflux disease, and the subject remains very complex and controversial. ${ }^{26}$ Empirical treatment without any investigation may be appropriate for patients with uncomplicated symptoms of heartburn or reflux.

\section{Generalisability of findings}

Are the results of our study generalisable to other regions and populations? The prevalence of infection with $H$ pylori in our patients with dyspepsia was approximately $50 \%$, which is similar to the mean value of $55.2 \%$ reported in a large meta-analysis of the prevalence of $H$ pylori in patients with non-ulcer dyspepsia. ${ }^{27}$ However, the prevalence of the infection varies considerably, depending largely on the socioeconomic status and age of the group being studied. ${ }^{28}$ Subanalysis indicated that the two strategies were of equivalent efficacy, irrespective of $H$ pylori status at presentation. However, in populations with a very low prevalence of the infection and of $H$ pylori related ulcer disease, both investigation strategies may be superfluous.

\section{Previous studies}

Only one previous study randomised patients with upper gastrointestinal symptoms to non-invasive $H$ pylori testing or endoscopy. ${ }^{29}$ That study, by Lassen et al, concluded that the test and eradicate $H$ pylori strategy was as efficient and safe as prompt endoscopy. However, it did find that slightly fewer patients were very satisfied one year after non-invasive $H$ pylor $i$ testing $(56 \%)$ than after endoscopy $(62 \%)$. In contrast, we found that satisfaction was similar after the two strategies, and this may be related to our specialist team providing the patients with a fuller description of the relative merits of the two modes of investigation.

One previous study compared the cost of management by non-invasive $H$ pylori testing or by endoscopy by randomising general practices to the two investigation strategies. ${ }^{30}$ The study included patients aged under 45 with ulcer-like symptoms for more than four weeks, without alarm symptoms, and in whom the gen- 
eral practitioner considered further investigation appropriate. Over the 12 months after randomisation, the total cost of consultations, referrals, investigations, and treatment was on average $£ 404.31$ in the endoscopy group compared with only $£ 205.67$ in the non-invasive $H$ pylori testing group.

Two smaller studies have compared H pylori testing with endoscopy in subgroups of patients with dyspepsia referred for endoscopy. Heaney et al randomised 500 patients aged under 45 referred to secondary care with ulcer-like dyspepsia and who had a positive $H$ pylori breath test to either $H$ pylori eradication or endoscopy and eradication of the infection in only those with ulcers. ${ }^{6}$ Over the one year follow up, the first group had superior relief of symptoms and a reduction of $75 \%$ in the use of endoscopy. A further study by Asante et al studied 154 patients aged under 45 with upper gastrointestinal symptoms, including heartburn or reflux symptoms, who were referred for open access endoscopy and found to have a negative result on serological testing for $H$ pylori. ${ }^{4}$ The patients were randomised to endoscopy or no endoscopy and followed up for two years. No differences were found between the two investigation strategies with respect to resolution of dyspepsia, use of drugs, or visits to the general practitioner. Use of endoscopy was reduced by $83 \%$ over the two year follow up.

\section{Conclusion}

Our current study and the previous studies, therefore, all indicate that non-invasive testing for $H$ pylori is as effective as endoscopy in managing patients with uncomplicated upper gastrointestinal symptoms. The nonendoscopic strategy has two potential benefits. The first is that patients find the procedure of non-invasive $H$ pylori testing less uncomfortable and distressing than endoscopic examination. The second is that noninvasive $H$ pylori testing is substantially cheaper than endoscopy. For these reasons, non-invasive $H$ pylori testing seems to be the preferred investigation for patients with uncomplicated dyspepsia.

Finally, it should be emphasised that our study provides information on the relative merits of only two investigational strategies. It is likely that other approaches, such as empirical treatment without investigation or the use of other investigations, will be more appropriate for certain patients.

Contributors: KELMCC, LSM, DG, and AD designed and conducted the study. AW, JF, EH, and CM contributed to the conduct of the study. LSM analysed the data. AK facilitated the data transfer. AW assisted with the analysis. KELMcC and LSM wrote the paper. KELMCC is the guarantor.

Funding: The study was commissioned and funded by the NHS Executive research and development technology assessment programme. The views expressed in this paper are those of the authors and not necessarily those of the Department of Health.

Competing interests: None declared.

1 Ryder SD, O'Reilly S, Miller RJ, Ross J, Jacyna MR, Levi AJ. Long term acid suppressing treatment in general practice. BMJ 1994;308:827-30.

2 Ofman JJ, Rabeneck L. The effectiveness of endoscopy in the management of dyspepsia: a qualitative systematic review. Am J Med 1999;106:335-46.

3 McColl KEL, El-Nujumi A, Murray L, El-Omar E, Gillen D, Dickson A, et al. The Helicobacter pylori breath test: a surrogate marker for peptic ulcer disease in dyspeptic patients. Gut 1997;40:302-6.

4 Asante MA, Mendall M, Patel P, Ballam L, Northfield TC. A randomized trial of endoscopy vs no endoscopy in the management of seronegative Helicobacter pylori dyspepsia. Eur J Gastroenterol Hepatol 1998;10:983-9.

\section{What is already known on this topic}

Endoscopy is a commonly used investigation for upper gastrointestinal symptoms, but its effectiveness has been questioned

Non-invasive testing for Helicobacter pylori has been shown to predict endoscopic diagnosis in patients with dyspepsia

\section{What this study adds}

In patients less than 55 years of age with uncomplicated dyspepsia, non-invasive testing for H pylori is as effective and as safe as endoscopy

Non-invasive $H$ pylori testing is as reassuring to the patient as endoscopy and is less uncomfortable and distressing

5 Patel P, Khulusi S, Mendall MA, Lloyd R, Jazrawi R, Maxwell JD, et al. Prospective screening of dyspeptic patients by Helicobacter pylori serology. Lancet 1995;346:1315-8.

6 Heaney A, Collins JSA, Watson RGP, McFarland RJ, Bamford KB, Tham TCK. A prospective randomised trial of a "test and treat" policy versus endoscopy based management in young Helicobacter pylori positive patients with ulcer-like dyspepsia, referred to a hospital clinic. Gu 1999;45:186-90.

7 Moayyedi P, Soo S, Deeks J, Forman D, Mason J, Innes M, et al on behalf of the Dyspepsia Review Group. Systematic review and economic evaluation of Helicobacter pylori eradication treatment for non-ulcer dyspepsia. BMJ 2000;321:659-64.

8 Blum AL, Arnold R, Stolte M, Fischer M, Koelz HR, the Frosch Study Group. Short course acid suppressive treatment for patients with functional dyspepsia: results depend on Helicobacter pylori status. Gut 2000;47:473-80.

9 Talley NJ, Meineche-Schmidt V, Pare P, Duckworth M, Raisanen P, Pap A, et al. Efficacy of omeprazole in functional dyspepsia: double-blind, randomized, placebo-controlled trials (the Bond and Opera studies). Aliment Pharmacol Ther 1998;12:1055-65.

10 McColl KEL, Murray L, El-Omar E, Dickson A, El-Nujumi A, Wirz A, et al. Symptomatic benefit from eradicating Helicobacter pylori infection in patients with non-ulcer dyspepsia. N Engl J Med 1998;339:1869-74.

11 Blum AL, Talley NJ, O'Morain C, Veldhuyzen van Zanten S, Labenz J, Stolte M, et al. Lack of effect of treating Helicobacter pylori infection in patients with nonulcer dyspepsia. N Engl J Med 1998;339:1875-81.

12 Gilvarry J, Buckley MJM, Beattie S, Hamilton H, O'Morain CA Eradication of Helicobacter pylori affects symptoms in non-ulcer dyspepsia. Scand J Gastroenterol 1997;32:535-40.

13 Forman D, Newell DG, Fullerton F, Yarnell JWG, Stacey AR, Wald N, et al. Association between infection with Helicobacter pylori and risk of gastric cancer: evidence from a prospective investigation. BMJ 1991;302:1302-5.

14 Parsonnet J, Rodriguez L, Gelb AB, Warnke RA, Jellum E, Orentreich N, et al. Helicobacter pylori and gastric lymphoma. $N$ Engl $J$ Med 1994:330:1267-71.

15 Kuipers EJ, Lundell L, Klinkenberg EC, Havu N, Festen HPM, Liedman $\mathrm{B}$, et al. Atrophic gastritis and Helicobacter pylori infection in patients with reflux esophagitis treated with omeprazole or fundoplication. NEngl JMed 1996;334:1018-22.

16 El-Omar EM, Banerjee S, Wirz A, McColl KEL. The Glasgow dyspepsia severity score-a tool for the global measurement of dyspepsia. EurJ Gastroenterol Hepatol 1996;8:967-71.

17 Garratt AM, Ruta DA, Abdalla MI, Buckingham JK, Russell IT. The SF36 health survey questionnaire: an outcome measure suitable for routine use within the NHS? BMJ 1993;306:1440-4.

18 Mowat C, Murray L, Hilditch TE, Kelman A, Oien K, McColl KEL. Comparison of Helisal rapid blood test and 14C-urea breath test in determining Helicobacter pylori status and predicting ulcer disease in dyspeptic patients. Am J Gastroenterol 1998;93:20-5.

19 Jones R. What happens to patients with non-ulcer dyspepsia after endoscopy? Practitioner 1988;232:75-8.

20 Wiklund I, Glise H, Jerndal P, Carlsson J, Talley NJ. Does endoscopy have a positive impact on quality of life in dyspepsia? Gastrointest Endosc 1998;47:449-54

21 Gillen D, McColl KEL. Does concern about missing malignancy justify endoscopy in uncomplicated dyspepsia in patients aged less than 55 ? Am J Gastroenterol 1999:94:75-9.

22 Christie J, Shepherd NA, Codling BW, Valori RM. Gastric cancer below the age of 55: implications for screening patients with uncomplicated dyspepsia. Gut 1997;41:513-7.

23 Prach AT, MacDonald TA, Hopwood DA, Johnston DA. Increasing incidence of Barrett's oesophagus: education, enthusiasm, or epidemiology? Lancet 1997;350:933

24 Botterweck AAM, Schouten LJ, Volovics A, Dorant E, van den Brandt PA Trends in incidence of adenocarcinoma of the oesophagus and gastric cardia in ten European countries. Int J Epidemiol 2000;29:645-54. 
25 Weijnen CF, Numans ME, de Wit NJ, Smouth AJPM, Moons KGM, Verheij TJM, et al. Testing for Helicobacter pylori in dyspeptic patients suspected of peptic ulcer disease in primary care: cross sectional study. BMJ 2001;323:71-5.

26 Labenz J, Malfertheiner P. Helicobacter pylori in gastro-oesophageal reflux disease: causal agent, independent or protective factor? Gut 1997;41:277-80.

27 Jaakkimainen RL, Boyle E, Tudiver F. Is Helicobacter pylori associated with non-ulcer dyspepsia and will eradication improve symptoms? A meta-analysis. BMJ 1999;319:1040-4.

28 Woodward M, Morrison C, McColl K. An investigation into factors associated with Helicobacter pylori infection. J Clin Epidemiol 2000;53:175-81.
29 Lassen AT, Pedersen FM, Bytzer P, Schaffalitzky de Muckadell OB. Helicobacter pylori test-and-eradicate versus prompt endoscopy for management of dyspeptic patients: a randomised trial. Lancet 2000;356:455-60.

30 Jones R, Tait C, Sladen G, Weston-Baker J. A trial of a test-and-treat strategy for Helicobacter pylori positive dyspeptic patients in general practice. Int J Clin Pract 1999;53:413-6.

(Accepted 2 February 2002) 